\title{
Developing a more effective regional planning framework in Egypt: the case of ecotourism
}

\author{
E. H. Kenawy ${ }^{1} \&$ D. Shaw ${ }^{2}$ \\ ${ }^{1}$ Faculty of Urban and Regional Planning, Cairo University, Egypt \\ ${ }^{2}$ Department of Geography and Planning, University of Liverpool, UK
}

\begin{abstract}
In Egypt, rational regional development plans are drawn up, but nobody puts them into practice. They end up gathering dust on the shelves. The main flaws in the current plan-making process are centred on the government's centrality and monopoly in decision-making; fragmentation between government agencies leading to multiple and often conflicting spatial plans for the same location; and an absence of negotiations between various stakeholders. These problems can be clearly demonstrated with reference to ecotourism planning. Such plans are being developed in highly sensitive regions, both environmentally and culturally, and there is a wide spectrum of stakeholders who are affected and influenced by any ecotourism development. Ecotourism development planning is a complex issue to the extent that it is beyond the capacity of any one stakeholder acting alone to resolve. The collaborative approach is an appropriate one, building consensus between the stakeholders, and developing solutions that are acceptable to all. By focusing on two case studies, the Fayoum and New Valley regions, and critiquing existing experiences of ecotourism regional planning, a collaborative ecotourism planning framework will be developed.
\end{abstract}

Keywords: planning process, collaborative approach, ecotourism, stakeholders, Egypt.

\section{Introduction}

During the last three decades, particularly after the spatial planning law was issued in 1982, spatial development plans have been produced but rarely implemented. Hundreds of thousands of dollars (from the national budget or international grants) have been spent in developing these plans but they gather 
dust on the shelves of the national agencies or local governments without improving local economic or environmental well-being. An informal survey, conducted by the authors, with nine key Egyptian development planning experts found that inadequacy of planning process was the major factor impeding the implementation of the plans. The current process and practice is centred on national government centrality and monopoly in decision-making and does not involve relevant regional and local stakeholders nor deal with their conflicts.

Moreover, the fragmentation between national government Departments and Agencies combined with competition for the same resources [1] leads to multiple and frequent plans being prepared for the same location under different names. This then leads to incongruous and incompatible proposals for land use, a failure to make decisions about development the loss of potential economic benefits and environmental quality. These plans are produced to a high technical standard by consultants, they do rarely meet the interests of relevant stakeholders and nobody puts them into practice. Without a system to facilitate negotiation and a building of consensus between the stakeholders, this failure cannot be addressed. But in addition the stakeholders also resist the implementation of the plans [2]. According to Kamarudin [3], one way to overcome these problems may be by promoting communication and collaboration within and between institutions, as well as broadening stakeholders' participation during the planning process. The collaborative planning approach (CPA) is exalted as one of the best methods to address this fragmented and highly centralised decision making [4] particularly in developing countries such as Egypt. It can resolve the conflicts between stakeholders and produce more shared and equitable solutions. However, the major contribution of CPA is that it improves the legitimacy and quality of decision-making, as well as building integration among and between governmental and non-governmental stakeholders [5].

Egyptian ecotourism development (ED) is used as a case study for several reasons: i) such plans are being developed in highly sensitive regions, both environmentally and culturally, and there is a wide spectrum of stakeholders who are affected and influenced by any ecotourism development [6]; ii) ED planning is a complex issue; no single actor has all the knowledge and information required to resolve an issue; iii) ED is seen as being important for Egypt in mitigating the issues of mass-tourism strategies which have led to Egyptian tourism products being perceived as low-price and low-quality [7]; iv) well planned and implemented ED could maximise the benefits from the Environmental Sensitive Areas which represent more than $17 \%$ of the country's total area [8]; and v) ED also provides opportunities to expand the Egyptian share of the global tourism market [9].

This paper aims to design a practical framework for operationalising a CPA in regional planning using ED as a case study. In order to achieve this aim, the first part of the paper establishes a conceptual framework for successful ED planning based upon an analytical review of the literature relevant. Two ED planning process case studies are then evaluated in the second part of the paper. The paper concludes by developing a practical collaborative ecotourism planning (CEP) framework by comparing the theoretical approach with practice. 


\section{Developing a conceptual framework}

\subsection{Collaborative planning approach}

CP is a relatively recent approach, which emerged in the 1990s as a response to the deficits in traditional planning approaches which revolved around the central role of an expert. The key deficit of the traditional process was its inability for the experts to harmonise inter-stakeholder conflicts [2]. CP is a collective process for resolving conflicts and advancing a shared vision involving a wide range of stakeholders working together through face-to-face dialogue [10]. Furthermore, CP should be horizontally and vertically structured. The process should include all stakeholders at different levels of governance who have a stake in the issue [11] to produce a better plan and increase the likelihood of successful implementation because of stakeholder buy-in [12]. CP deals with development potentials in a holistic and multi-disciplinary manner to try to achieve 'win-win' solutions. It ensures that stakeholders are involved not only at the beginning but throughout the whole process and have a voice in both framing the problem and in shaping solutions [11]. According to Gray [13] and others (i.e. [10]), the incentives for using CP are: the increasing pressures on the environment and local communities, shrinking the state's abilities to solve social problems, and blurring the boundaries between the public, private and community sectors, particular at the local scale. Although CP is time-consuming, delays the process and reduces plan efficiency, it has been widely recognised as an essential ingredient in the development planning process for two main reasons: i) CP devolves the power from governmental institutions by providing stakeholders with specific responsibilities both during the planning and implementation processes [14]; and ii) it provides educational opportunities for improving stakeholder skills in dealing with planning issues [15].

\subsection{Ecotourism context}

Ecotourism is a sub-set of the sustainable tourism field. It primarily includes natural, rural and cultural tourism elements that are consistent with environmental, social and community values. Additionally, ecotourism is often considered to be a potential strategy for promoting a combination of visitor/tourist satisfaction, local benefits, and proactive conservation of local natural and cultural resources [16]. ED has been depicted as a system that promotes the organic interrelationships [14] between three subsystems: ecotourism (services, activities and infrastructure), natural and cultural diversity, and local communities [17]. Furthermore, there are several stakeholders who are affected and influenced by the ecotourism system, e.g., public sector, private sector and local people. Ensuring balanced relationships between ecotourism system components during the development requires effective collaboration among the relevant stakeholders within the process. This balance is very unlikely to occur without the stakeholders committing to and implementing the development plan. 


\subsection{The conceptual framework}

Because stakeholder involvement is viewed as an essential component in the CP process, the success of the process can be measured by the degree of their involvement their influence on the decision making, and the development of a shared vision that reflects their interests. So there are three main questions to be considered within the process. Who should be involved? When should they be involved? How should they be involved? [4]. The first question is concerned with identifying who are interested in, and influenced by, the issues. The network is one of the main means of ensuring continuous interactive communication and negotiations between the stakeholders as well as facilitating mutual learning and development skills between them [18]. This network promotes and supports bridge building between the various stakeholders. Identifying and analysing the stakeholders during network building phase has been felt by experienced conveners to have a critical roles in managing relations and building consensus through the $\mathrm{CP}$ process [19]. The second question concerns the stakeholder involvement during the process and is concerned with which phase and level of involvement takes place based on Arnstein's ladder of participation [20]. The stakeholders should be fully integrated throughout the planning process from informing level to decision making, implementation and monitoring process [4]. Further, stakeholders should be chosen to participate in the different levels relative to their influence and interests in order to reduce the complexity and gain more control and efficiency. The question of how to involve them is largely concerned with the engagement techniques: effective stakeholder engagement requires a combination of appropriate methods at each step of the planning process for a more pro-active exchange of information and views [21]. These methods should be varied to motivate the specifically targeted stakeholders. Frequently used traditional methods may for example, exclude people uncomfortable with meetings [22].

Further to this, a preparation stage is required to educate stakeholders about key principles of ecotourism development and provide them with helpful information about their engagement [23]. Additionally, due to past promises often going unmet, as well as corruption within the controlling bureaucracy in stakeholders, particularly in developing countries need to be encouraged and motivated to engage with the process [14]. Therefore, a successful CP process should be concerned with the appropriate motivation strategies for each stakeholder group to help ensure their participation during the process. The process and outcomes of the $\mathrm{CP}$ need to be constantly evaluated to determine whether the stakeholder inputs have been successful in accomplishing their objectives and systematically adjusted during the process to improve outcomes [24].

Consequently, the analysis of the ecotourism initiative based on the conceptual framework contains four main elements, as Figure 1 shows: a) an investigation of the stakeholder network building process; b) an examination of the stakeholder engagement during the planning process; c) an evaluation of the process and its outcomes; and d) an identification of the barriers to stakeholder involvement and collaboration. 


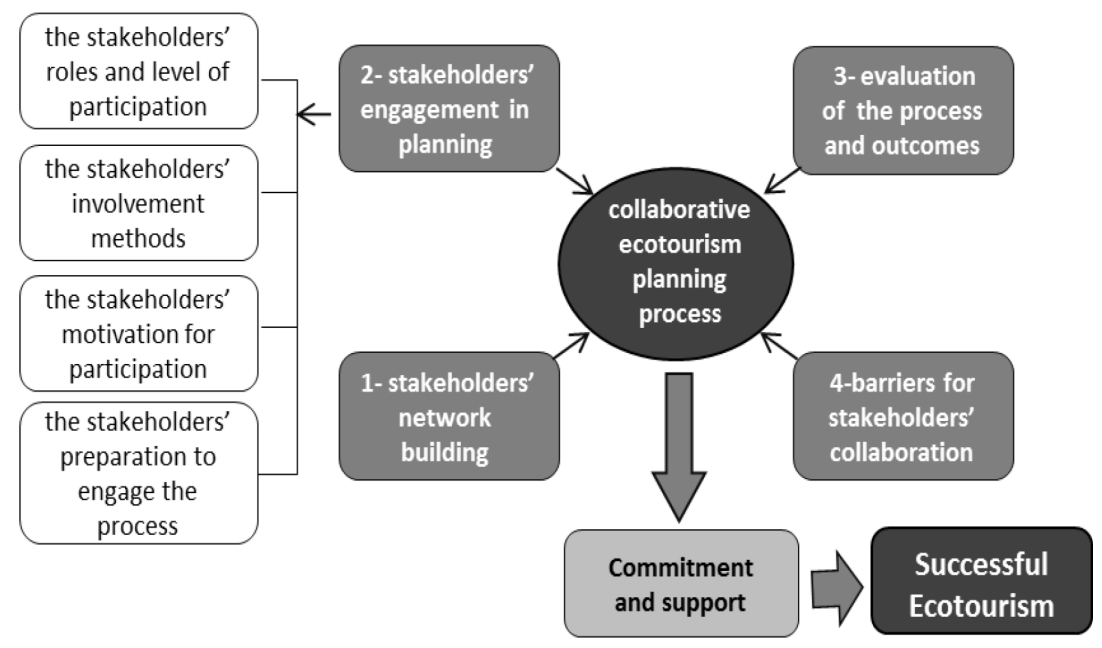

Figure 1: The conceptual framework.

\section{Methodology}

A case study approach was adopted to examine whether conceptual framework could be applied in practice. Evidence from the case studies were drawn from a critical documentary review of two Egyptian ecotourism planning initiatives, combined with semi-structured interviews with fifty ecotourism experts and stakeholders.

\section{Evaluating the Egyptian ecotourism planning initiatives}

The establishment of ecotourism development plans was first initiated in Egypt in 1991, but it did not adapt ecotourism as a new strategy for tourism development until 2002. This was after the World Ecotourism Summit recommendations which obligated all participating countries (including Egypt) to formulate national, regional and local ecotourism development strategies. Egypt has since developed dozens of initiatives for ecotourism planning in environmentally vulnerable regions.

This paper has chosen the two most recent projects as cases studies for this research: Fayoum Ecotourism Development Plan 2005-2015 (FEDP) was prepared in 2008 and Ecotourism for Sustainable Development in the New Valley Governorate (ESDNVG) was prepared in 2012. Both are located in the western desert, which includes nature, culture and heritage-based activities which provide a unique personal experience for ecotourists. 


\subsection{Evaluating FEDP and ESDNVG initiatives}

This part aims to evaluate the initiatives through the lens of the conceptual framework to identify gaps in the planning process and the obstacles in applying the CEP in Egypt.

\subsubsection{Stakeholder network building}

In both initiatives, multi-actor conveners including three representatives of the regional tourism authority, the funder and the planning team [25] identified the stakeholders required to build the network. Both convener teams had the power and legitimacy to bring stakeholders to the table, derived from long experience and because they were independent experts and not representatives of the government office, as Getz and Jamal [26] had observed there was a great deal of stakeholder mistrust of the government because of previous negative experiences.

The stakeholder networks were composed of two sub-networks: an internal network, which included the relevant actors located within the project boundaries; and an external network, which was considered complementary, and includes stakeholders from the outside the local region, such as national and global actors [27].

Identifying the internal stakeholders; in both initiatives this process began by identifying the list of the relevant stakeholder groups then requesting a nominated representative from each group. The list of stakeholder groups for each initiative was slightly different and significant groups were missing from both lists. Hence, one interviewee remarked that "the lists for both initiatives excluded some important and relevant agencies such as the General Organization for Physical Planning, which prepares several future plans and has an up-to-date database for the key infrastructure in each location". Similarly, the local planning offices in the separate Governorates and relevant city municipal administrations were not included even though these bodies were in theory in charge of implementing the plans.

In relation to the stakeholder identification techniques used for each list, there were also slight differences. In the FEDP, the conveners and planning team identified the list of stakeholders based on reviewing the documents of previous tourism plans and their long experience in the Fayoum. The ESDNVG initiative established an initial meeting with the main readily identified partners of ecotourism development such as New Valley Tourism Authority and the Governorate to define other possible relevant actors of ecotourism development by using a snowball technique.

With regards to nominating the specific representatives from each stakeholder group, representatives from the public sector bodies in both initiatives were nominated exclusively by the chief of each agency without any input from the conveners because they were not familiar with the detailed administrative structure of each agency nor the skills and knowledge of employees at each level. Furthermore any interference by the convenors in this process would be considered by the agency chiefs as an intervention in their internal affairs and then they would refuse to participate in the process. Therefore, often their 
nominated representatives had little or no knowledge about ecotourism development and their participation through the process was not effective because they had no decision making authority and were only observers.

Local community representatives in FEDP were identified following intensive field investigations with the craft producers which led to nominations via informal interviews and face-to-face discussions. But not all community groups in the Fayoum region, particularly those adjacent to the main areas with ecotourism potential were included in this process. In the ESDNVG the local community delegates were nominated using a snowball technique starting with the most famous and main artisans drawn from the NV communities.

Although the private sector will be critical to an effective ecotourism planning and implementing process, because of their long experience in the tourism market and their understanding and promotion of potential business opportunities which will attract their investment, it is interest to not how in practice their involvement in the planning process was very limited. In the FEDP, only a few ecolodge owners were invited as representatives of the private sector [28]. The ESDNVG also only invited a few representatives from hoteliers, small entrepreneurs and local guides [25]. A much fuller and worthwhile contribution of the private sector in the process could have been better facilitated by the Egyptian Tourism Federation (ETF) because it has a solid database and excellent relations with key persons from the tourism industry bodies.

NGOs involvement in both initiatives was very limited and not effective for two reasons: i) the majority of NGOs in Egypt are primarily interested in providing social services for needy people. There are few qualified and experienced NGOs working in the fields of ecotourism or environmental planning; and ii) there is no culture in Egypt which promotes the organisation, evaluation and development of NGOs working in the fields of the natural, cultural and tourism, contexts and thereby complementing the role of the state.

Analysing the internal stakeholders; Due to the wide range of stakeholders who are potentially interested in regional ecotourism development, an analysis of all the key stakeholders is a crucial step in building the network to categorise and define their role during the planning process, as well as identifying gaps in stakeholder so that a balance between underrepresented and overrepresented stakeholders can be achieved [21]. However neither initiative followed any known analysis techniques to achieve this balance. The conveners and planning team classified the stakeholders based on either the level of positions (top executive, first line of decision makers and regional/local executive employees) or sector (public, private, local community and NGOs) [25]. They were all considered as having the same degree of importance, although each stakeholder had a variety of different interests, influences and power for planning issues.

In both FEDP and ESDNVG projects, stakeholders were managed throughout the majority of the project activities as separate but essentially a homogenous (i.e. coming from similar backgrounds, culture and positions) groups [25]. Any success in the negotiation between these groups was based mainly on the convener bringing different stakeholder views together. Consequently, the classification method used in both initiatives could be considered as the first 
step in building a consensus between the stakeholders, but these groups really needed to be brought together in order to that true collaboration and a real mitigation of the conflicts of interests could be achieved as the foundation for building joint commitment for implementation.

The external stakeholder networks; these networks are just as important for a successful planning process as internal ones. Their support for ecotourism development can assume various forms depending on the type of organisation involved such as co-financing, major experience, political influence, training and media, etc. [27]. However, neither initiative really included any external actors, whether global or national, except ETF (which is an example of a national NGO), during the FEDP process. However in this case the convener did not define those aspects that the ETF could contribute too or support. As one of the interviewees remarked "there are a huge number of international governmental and non-governmental organisations who are interested in assisting development in Egypt whether from a technical or financial perspective such UNDP, UNTWO and UNESCO, etc. However, they were not invited to participate in any of the initiatives".

Dialogue between stakeholder group representatives (SGRs) and their parent bodies; Dialogue between SGRs and their parent bodies during the planning process is very important if the outcomes of the planning are to be accepted and not ignored or disregarded in the future [13]. These dialogues within each of the ecotourism initiatives varied from one stakeholder group to another. In the FEDP, the dialogues between the governmental authorities and their SGRs were not good. The normal communication technique was written summary reports from the SGRs to their managers after each meeting held had been completed. But there was a lack of feedback and no guidance given to the SGRs in terms of what, if anything they should say as part of future negotiations. However, with the private sector agencies during the FEDP process dialogue between the SGRs and the organisations they represented were more pro-active. There was feedback and guidance given after each meeting so that the representatives could negotiate throughout the process to best represent the interests of that particular. For those individuals invited to represent the interests of local people, handicraft groups or NGOs the individuals offered only their own opinions without engaging in dialogue with other members of the group [28].

In relation to the ESDNVG there was limited consultation of SGRs and the constituencies that they were supposed to represent. For example, the majority of the governmental representatives were not accountable because they were the appointed chairmen of the regional or local offices. They rarely reported back to or consulted with the bodies they were supposed to represent. Furthermore, there was no dialogue within the other stakeholder groups (private sector, local community, and NGOs) during the process [25].

\subsubsection{Stakeholders' engagement with the planning process}

Stakeholders roles and their level of participation throughout the planning process; Stakeholders participation in both initiatives can be seen as tokenism, 
at least judged against Arnstein's [20] ladder of participation. It was confined to three levels only, namely: informing, consultation and co-producing.

i) Informing means sharing the information in two directions between stakeholders and planning team. The first direction was informing, telling the stakeholders about the planning activities but without giving them any chance to provide feedback [21]. Only ESDNVG produced six-monthly newsletters to help inform the stakeholders. However these were of extremely limited value because they were written in English and not accessible to the key audiences because either they were illiterate or could not speak English. The second direction of informing was getting information from the stakeholders. This was a good opportunity for contacting local communities which were intended to provide the main source of local information. FEDP used informal interviews and intensive field investigation to identify the constraints and potentials for ecotourism development in the Fayoum [28]. Similarly, for ESDNVG the planning team conducted a field survey throughout the study areas. However, the stakeholders were involved only in completing what was identified as being missing data.

ii) The second level of engagement was consultation. Its role was to widen stakeholder participation through an involvement of key legitimate stakeholders who had been left outside the formal stakeholder network. However these consultation events in FEDP did not increase the stakeholder participation because the majority of the attendees at these consultation activities were already participating in the process. In ESDNVG, no formal consultation meetings were held although the convener tried to use a questionnaire to get feedback from the stakeholders beyond the network. But this proved an unsuccessful technique to explore their views.

iii) The third approach to participation was co-production the method whereby stakeholders, decision makers and planners could jointly agree on adequate solutions [21]. However, in both initiatives the majority of stakeholders never participated in such activities. In FEDP, the middle governmental employees shared the production of the final plan with the planning team without inviting other stakeholder groups. In ESDNVG, the outcomes were produced in a different way. The stakeholders' role in this stage was just as an advisor for the planning groups. The planning team, then simply produced the final plan without returning to the stakeholders to gain their views on the proposed outcomes.

With regards to stakeholder roles during the planning process, there was no clear role for them during either initiative, except for the focal actors of the government agencies such as the Tourism Development Authority.

Stakeholder involvement methods; in both cases the main methods of stakeholder engagement focused on informing and training the stakeholders rather than actively involving them so that they had an input into decisionmaking. Hence one of the interviewees claimed that "informing or education techniques could not alone fulfil the requirements of a collaborative approach for ecotourism planning". In relation to the appropriateness and sufficiency of the method at each phase of the process the following observations can be made: 
i) The diagnosis phase consisted of two methods, face-to-face interview and a survey, which might be appropriate for single or small scale traditional communities but were not sufficient for large-scale developments with geographically dispersed stakeholders such as the FEDP and the ESDNVG. A second involvement method was public meeting designed to introduce both initiatives to interested stakeholders. These took place but were largely tokenistic because too little information was passed to the stakeholders because of the large number of attendees and the very limited time devoted to respond to various stakeholder concerns.

ii) The analysis phase also involved two main techniques: The ESDNVG initiative provided a good example of using workshops to involve the stakeholders during the analysis phase. But in FEDP they faced drawbacks because of the large number of attendees. This meant that not all of the participants were given sufficient time to provide their input into the discussion [28]. Secondly, a questionnaire could be used, but this only happened in ESDNVG. But in practice this was not an appropriate technique to gain meaningful input during the analysis phase [25] because the respondents answers were very brief and careless.

iii) The development phase included three different involvement events. In ESDNVG, a best practice exchange between the stakeholders from the Fayoum and the NVG was an appropriate and effective educating event. But in both initiatives, the workshops suffered from the same drawbacks mentioned earlier regarding feedback and a two way rather than a one way direction of information (from the convenor to the stakeholders). Also, one public meeting was not sufficient for large-scale development with geographically dispersed stakeholders. As a result participant feedback was very limited because the majority of them did not know anything about the initiative before.

Furthermore there were other key deficiencies that affected the effectiveness of the meetings such as: i) the time of the meetings was inappropriate for the stakeholders as they took place during work time meaning that many could not get time off work and subsequently attend; ii) the structure of the meeting were organised in such a way that they did not give the stakeholders enough time to provide their inputs; and iii) there was a lack of follow-up so that the stakeholders were kept informed of meeting outcomes.

Stakeholder motivation to be involved in the process; ESDNVG was the only initiative that used two different motivation techniques: fiscal incentives to the local communities and providing the private sector with access to the database of NVG ecotourism resources [25]. However, neither approach was really sufficient. The fiscal incentive was proved equally to all those that attended and was not linked to their inputs into the process. Furthermore the money was not really appropriate for the community leaders. Providing real legitimacy for them to engage or psychological motivations were needed more than money. In relation to making the database available to the private sector was insufficient because it came too late in the process- two years after the project had commenced. 
The stakeholders preparedness for engagement; in Egypt, ecotourism development characteristics are not well known, and many of the stakeholders were not really qualified to participate in the planning process nor were they prepare before their engagement in the planning process began. Most of preparation events in both initiatives focused on raising awareness amongst stakeholders about running ecotourism activities, moreover such activities usually took too late within both initiatives being located at the middle or at the end of the process [25]. Likewise, the local communities of both initiatives are predominantly traditional and indigenous and they needed significant efforts to raise their awareness about ecotourism and determine their roles during the process. However, none of the initiatives really provided enough attention for these participants.

\subsubsection{The evaluation procedures}

Evaluation was one of the weakest parts of the planning process in both initiatives. Any evaluation of previous ecotourism initiatives to identify any potential lessons and within both of the initiatives described here reflection on either the process or outcomes both initiatives were very limited at best.

\subsubsection{Barriers to stakeholder involvement and collaboration}

In addition to the aforementioned deficiencies already described in previous sections, there were some barriers associated with the governmental and nongovernmental stakeholders that create hurdles to their effective participation and collaboration. Understanding and anticipating these barriers should be significant for promoting more effective stakeholder involvement during the planning process.

Deficiencies in the government; there are a number of challenges facing governmental engagement which includes: i) centralisation in the system public administration; ii) a lack of coordination between the governmental authorities and the coordinating bodies do not have a legal mandate to harmonise intergovernmental conflicts; iii) a lack of information which is furthermore scattered across many government agencies. They often collect data separately leading to duplication of effort; iv) a lack of financial resources to initiate or support the planning process for ecotourism development. As the international funding for both of these (and other) initiatives was for the planning process only, the processes stopped once the funding ended; v) the lack of capacity within the staff of governmental bodies whether at central, regional and local levels; and vi) the lack of an appropriate legal framework; due to the ecotourism areas being located under the jurisdiction of several agencies they are governed by various legislations.

Deficiencies in the local communities and other stakeholders; these include: i) a lack of trust in the government as a result of negative experiences and previous unmet promises; ii) a lack of awareness about the importance of ecotourism development and the benefits of their participation; and iii) widespread illiteracy and low standard of living, so the major concerns from these 
stakeholders are their daily needs and providing the basic public services rather than future prospects.

\section{The practical framework for CEP}

Based on this analysis we suggest a new framework which adds two phases (1 and 4) to Gray's [13] CP model. There are a number of considerations that should be acknowledged during developing a CEP framework. These include: ii) harmonising and maintaining close links between the stakeholders through a good network and maintain relationships as well as regular dialogue between the SGRs and their agencies; ii) organising the process through an agenda reflecting all the stakeholder views; and iii) an experienced and neutral convener who will be significant in applying and achieving the overall objectives of the CEP framework. The CEP framework will include five inter-connected stages. There need to be overlapping and iterative links between them.

1. The initiation phase has been proposed to overcome several barriers such as the fragmentation between the stakeholders, lack of awareness and trying to overcome the negative response of stakeholders regarding their participation. This phase includes: i) building the internal and external stakeholders' network and, breaking the ice and starting to build the relations between them; ii) preparing the stakeholders for participation in the process; iii) evaluating previous similar experiences; and iv) trying to be clear about a specification of the end products (tangible and intangible outcomes) of the initiative.

2. Problem setting seeks to identify, understand, and then crystallise the issue after face-to-face dialogue. The main activities will be: i) ensuring common problem definition; ii) building commitment to collaboration; and iii) identifying the resources to ensure that these are sufficient to ensure the required negotiation activities can be completed [19].

3. Direction setting seeks to advance a shared direction for the future through: i) organising the procedures through establishing ground rules and agenda setting; ii) promoting joint information searches; iii) exploring options and reaching agreements; and iv) advocating a dispersion of power.

4. The promotion phase will be preparing for implementation. In this stage attempts need to be made to mitigate potential implementation challenges such lack of financial resources, inadequate products for the ecotourism market and reconciling conflicting responsibilities between stakeholders. The promotion group will be composed of primary and high-ranking actors to try and assist in mitigating these problems during the implementation phase. The main activities will be: i) evaluating the initial outcomes; ii) assigning financial resources for implementation; iii) marketing the outcomes to test their adequacy; and iv) raising awareness among the stakeholders of the implementation needs.

5. The implementation phase is to put the shared planning agreements into practical actions [26]. The main activities will be: i) phasing the final product; ii) defining the monitoring the implementation mechanisms; iii) 
selecting a suitable structure for institutionalising the implementation process; iv) harmonising the conflict between the public agencies in terms of their land jurisdiction and responsibilities; and v) building external support.

\section{Conclusions and future research}

This paper has identified the importance of CPA for enhancing planning and implementation in Egypt with particular reference to ecotourism planning. It proposes a conceptual framework and has identified four elements for analysing and evaluating stakeholder involvement. Drawing on the evidence from two ecotourism planning case studies gaps in the current planning processes, as well as the barriers which have hindered the efficiency of stakeholder participation have been identified. The analysis of the two initiatives revealed that ESDNVG performed slightly better than the FEDP, although both initiatives performed similarly on the building of stakeholder network. However, there were very few differences in practice including stakeholder roles during the different stages of the process, the involvement methods, stakeholder preparedness and their motivation for engagement.

Finally, a practical framework for CEP can suggested as the basis for further research in operationalising a CPA for ecotourism planning and development. It can be used as a framework for filling in the identified gaps in the process. But how some of the barriers can be pragmatically overcome need to be addressed through further research. Additionally since the research was undertaken Egypt was and continues to be afflicted by political instability and what impact this has on tourism development more generally and ecotourism in particular and stakeholders willingness to become involved in future orientated planning strategies is uncertain. Once stability returns further research will help complement this paper to enhance the implementation of plans in Egypt in particular and developing countries more generally.

\section{References}

[1] Loughlin, J. and M. Nada, Do we Need To Rethink Egypt's Territorial Governance and Planning for Economic Development? in the Strategic National Development Support project, UN-Habitat, Ministry of Housing \& Utilities and Urban Development and Ministry of Local Development. p. 167, 2012.

[2] Bonilla, J.C., Participatory Planning for Sustainable Cruise Ship Tourism in Mesoamerican Reef Destinations, in Second International Conference on Responsible Tourism in Destinations: Kerala, India, 2008.

[3] Kamarudin, K.H., Local stakeholders participation in developing sustainable community based rural tourism (CBRT): the case of three villages in the East Coast of Malaysia, in International Conference on Tourism Development, University Sains Malaysia Penang: G. Hotel Penang,Malaysia, 2013. 
[4] Monjardin, L., A collaborative approach to water allocation in a coastal zone of Mexico, in Civic Design Department, University of Liverpool, 2004.

[5] Jarvis, R., Collaboration as a strategy for developing cross-cutting policy themes: Sustainable Development in the Wales Spatial Plan, in Department of Civic Design, University of Liverpool, 2007.

[6] Preskill, H. and N. Jones, A Practical Guide for Engaging Stakeholders in Developing Evaluation Questions, in Evaluation series, Robert Wood Johnson Foundation: Princeton, USA, 2009.

[7] Chemonics, Destination management framework - enhancing the competitiveness of the South Red Sea of Egypt, in Egypt LIFE Red Sea Project, Chemonics International Inc, 2006.

[8] Ibrahim, M., Protected Areas in Egypt. Second ed, MSEA: EEAA, 2011.

[9] WEF, The Travel \& Tourism Competitiveness Report B.T. Jennifer, Chiesa, Editor, World Economic Forum: Geneva, Switzerland, 2011.

[10] Kim, J.S., A collabrative partnership approach to integrated waterside revitalisation: the experience of the Mersey Basin Campaign, North West of England, in Civic Design Department, University of Liverpool, 2002.

[11] Godwin, D.V., Collaboration as a Tool for Creating Sustainable Natural Resource Based Economies in Rural Areas, in Urban and Regional Planning, Virginia Polytechnic Institute and State University, 1999.

[12] Albert, K., T. Gunton, and J.C. Day. Achieving Effective Implementation: An Evaluation of a Collaborative Land Use Planning Process. 2003 01/12/2003 12/08/2013]; Available from:

http://www.thefreelibrary.com/Achieving effective implementation: an evaluation of a collaborative...-a0114604591.

[13] Gray, B., collaborating finding common ground for multiparty problems. First ed, San Francisco, USA: Jossey-Bass Inc, 1989.

[14] Araujo, L.M.d., Stakeholder Participation in Regional Tourism Planning: Brazil's Costa Dourada Project, Sheffield Hallam University: Sheffield, Uk. p. 375, 2000.

[15] Lima, I.B.d., The Micro Geopolitics of Ecotourism Competing Discourses and Collaboration in New Zealand and Brazil, in Department of Geography, Tourism and Environmental Planning, The University of Waikato, Hamilton, New Zealand, 2008.

[16] Wood, M.E., Ecotourism: Principles, Practices \& Policies for Sustainability: United Nations Publication. p. 32, 2002.

[17] Ross and Wall, Ecotourism: towards congruence between theory and practice. Tourism Management, 20(1): p. 123-132, 1999.

[18] Morton, C., Evaluating collaborative planning: a case study of the Morice land and resource management plan, in School of Resource and Environmental Management 2009, Simon Fraser University.

[19] Jamal, T. and A. Stronza, Collaboration theory and tourism practice in protected areas: stakeholders, structuring and sustainability. Journal of Sustainable Tourism, 17(2): p. 169-189, 2009. 
[20] Arnstein, S., A ladder of citizen participation. Journal of the American Institute of Planning, 1969. 35(4): p. 216-224.

[21] Taschner, S. and M. Fiedler, Stakeholder Involvement Handbook, in Attaining Energy Efficient Mobility in an Ageing Society, 2009.

[22] MDNR, A User's Guide to Watershed Planning in Maryland, Maryland Department of Natural Resources Watershed Services: Center for Watershed Protection, 2005.

[23] Cameron, J. and A. Johnson, Evaluation for development. Australian Planner, 41(1): p. 49-55, 2004.

[24] Kelly, C., S. Essex, and G. Glegg, Reflective practice for marine planning: A case study of marine nature-based tourism partnerships. Marine Policy, 36(3): p. 769-781, 2012.

[25] CISS and EDG, Ecotourism for sustainable development in the New Valley Governorate, CISS \& Environmental Design Group: Egypt, 2012.

[26] Getz, D.J., Jamal T.B., The Environment-Community Symbiosis: A Case for Collaborative Tourism Planning. Journal of Sustainable Tourism, 2(3): p. 21, 1994.

[27] GIZ, capacity works, The Management Model for sustainable development, GIZ: German, 2011.

[28] CISS and EDG, Fayoum ecotourism development plan 2005-2015, Cooperation International South-South \& EDG: Egypt, 2008. 